\title{
El objeto tabla: un estudio epistemológico, cognitivo y didáctico
}

\author{
Autor: María Soledad Estrella R. \\ Tipo de tesis: Tesis doctoral \\ Directores: Dr. Arturo Mena Lorca y Dr. Dani Ben-Zvi \\ Departamento: Instituto de Matemáticas \\ Universidad: Pontificia Universidad Católica de Valparaíso \\ Programa: Doctorado en Didáctica de la Matemática \\ Fecha de presentación: 21 de enero de 2014 \\ Fecha de recepción: marzo 2015 • Aceptado: marzo 2015
}

\section{RESUMEN}

La investigación se enfoca en la tabla como objeto de aprendizaje que tratar en los primeros grados de la escuela, y específicamente busca respuestas a la interrogante de cómo se conceptualiza la tabla. El trabajo se estructuró de la siguiente manera: el capítulo 1 presenta la problemática que investigar en Educación Estadística, las preguntas de investigación y los objetivos de esta. El capítulo 2 presenta la revisión de literatura especializada pertinente a las tablas en Estadística, enfocada en las dificultades de aprendizaje que presenta el formato tabular y en las implicancias para su enseñanza. Además, muestra el referencial teórico de la investigación para lo cognitivo y lo didáctico. El capítulo 3 ofrece una visión panorámica del proceso de evolución histórica de las ideas sobre tablas, su connotación de herramienta humana y su surgimiento y desarrollo en diversas culturas y diferentes momentos de la historia, cuestiones que aportan al conocimiento sobre este objeto y sus alcances didácticos. Muestra la trayectoria de la tabla y su presencia como herramienta de almacenamiento, como herramienta de cálculo en sistemas de numeración y de metrología, como herramienta de análisis en ámbitos científicos y/o matemáticos y su relación con la génesis del número y del concepto de función. El capítulo 4 entrega el estatus escolar de la tabla. Aborda un objetivo epistemológico sobre la tabla como elemento significativo en el análisis de la circulación del conocimiento y en la normalización del saber. Aunando características del formato tabular desde la Informática y desde la Estadística se propone un modelo genérico para la tabla. Se indaga en aspectos cognitivos al estudiar las tablas como representaciones que sustentan la construcción de significados de los datos, y se identifican roles de los sujetos y procesos cognoscitivos asociados a las tablas estadísticas. Finaliza con el estudio del papel de la tabla en los ítems de una prueba internacional de primaria, y su estatus en el actual currículo chileno y en otros tres países. El capítulo 5 presenta cuatro estudios llevados a cabo y que aproximan a la comprensión del aprendizaje de la tabla en el nivel escolar. Se comienza con el análisis de las evidencias que emergen de las producciones de los alumnos y de la gestión docente en el mantenimiento de la exigencia de las tareas, dada una situación de análisis de datos. Se continúa con la caracterización de los tipos de lectura 
que demanda el tratamiento de las tablas, y se levantan categorías para conformar una taxonomía de comprensión propia para aquellas, la cual finalmente se pone a prueba. El capítulo 6 finaliza el trabajo de tesis con las conclusiones y hallazgos para una primera exploración del progresivo dominio de la conceptualización de la tabla por parte de alumnos en los primeros años de escolarización, bajo el amparo de los referentes teóricos y los resultados recabados.

La polisemia y complejidad de significados estadísticos y matemáticos del concepto tabla impulsó investigar el vínculo entre, por una parte, la estructura de conocimiento conceptual de tabla construido por la disciplina y, por otra, la estructura conceptual construida por los alumnos respecto a esta, en especial la tabla de frecuencia de nivel escolar. Para procurar describir los niveles iniciales de conceptualización de la tabla que tenían los alumnos, se adoptó la Teoría de Campos Conceptuales, especialmente porque Vergnaud coloca la atención en el sentido progresivo del concepto que el sujeto va conformando a través de las situaciones problemáticas, junto con el lenguaje y los símbolos, y porque su teoría valoriza el conocimiento implícito de los alumnos enfrentados en situación y se enfoca en reconstruir dicho conocimiento para hacerlo explícito.

Para el diseño de la situación de aprendizaje de la tabla se adoptó un modelo de Educación Estadística que promueve el razonamiento estadístico (Garfield y Ben-Zvi, 2008), y además una perspectiva de los procesos activados cuando se cambia de representación (Wild y Pfannkuch, 1999). Como sistema didáctico, también se colocó la mirada en los actos de mediación del profesor a través de la observación de las demandas cognitivas que promueve (Stein y Smith, 1998). Al amparo de estos referentes, nuestra investigación es una primera exploración del progresivo dominio de la conceptualización de la tabla por parte de alumnos de primaria.

Uno de los aportes de la investigación ha sido obtener evidencia de la trayectoria de un objeto, la tabla. Se presenta la tabla como objeto protomatemático, luego útil para estudiar otros objetos matemáticos, por tanto, un objeto paramatemático, y recientemente su estatus de objeto matemático, como estudio en sí mismo.

También es un aporte la Taxonomía de Comprensión de Tablas, la cual fue producto de varios antecedentes y análisis sistemáticos, tales como los roles del sujeto enfrentado a tablas, los flujos de lectura de tablas, el análisis del tipo de uso dado a las tablas según hitos históricos y el análisis de ítems de pruebas internacionales. El análisis de esta taxonomía involucró aspectos de fiabilidad y validez interna, de constructo y de contenido, y un análisis estadístico que diferencia esta taxonomía de una taxonomía de comprensión gráfica. 